\section{The Oxidation of Hydroquinone by Protonated Quinone}

\author{
OLE HAMMERICH ${ }^{a}$ and \\ VERNON D. PARKER ${ }^{b}$
}

Department of General and Organic Chemistry,
The H. C. Ørsted Institute, University of
Copenhagen, Universitetsparken 5,
DK-2100 Copenhagen, Denmark and ' ${ }^{b}$ Organic
Chemistry Laboratories, Norwegian Institute of
Technology, University of Trondheim, N-7034
Trondheim-NTH, Norway

The electrochemical oxidation of hydroquinone has been studied extensively in recent years. ${ }^{1-9}$ The overall half-reaction (1) can be considered to be the classical organic redox couple. The mechanism of

$\mathrm{H}_{2} \mathrm{Q} \rightleftarrows \mathrm{Q}+2 \mathrm{H}^{+}+2 \mathrm{e}^{-}$

the oxidation is complex and involves several coupled electron transfer and proton transfer equilibria. Quinones have been used as electron acceptors during the oxidation of aromatic compounds. ${ }^{10-13}$ In some cases ${ }^{10,11}$ protonated quinones have been implicated as the active oxidants. We now report data concerned with the reaction of hydroquinone with quinone in the presence of acids to produce two equivalents of hydroquinone cation radical.

We have shown that the reversible oxidation of phenols to the corresponding cation radicals can be achieved by conducting voltammetric measurements at low temperatures in solvents containing strong acids. ${ }^{14}$ The function of the acid was to slow down the thermodynamically favorable deprotonation reactions of the phenolic cation radicals. Applying this technique to the voltammetric oxidation of hydroquinone resulted in the voltammograms shown in Fig. 1. In dichloromethane in the absence of acid at $-50^{\circ} \mathrm{C}$, an irreversible two electron oxidation was observed (Fig. 1a). Little change in the voltammogram was observed when the oxidation was carried out in the presence of trifluoroacetic acid (TFA) as is evident in Fig. 1b. When methane sulfonic acid ( $4 \%$ ) was added to the same solution, a quasi-reversible two electron oxidation was observed (Fig. 1c). The separation in the peak potentials for the oxidation and reduction processes was found to be dependent upon the acid concentration indicating that reversible protonation was involved. A voltammogram similar to that shown in Fig. 1c could be obtained during the reduction of quinone in dichloromethane containing varying amounts of $\mathrm{HFSO}_{3}$ at $-50{ }^{\circ} \mathrm{C}$. In a solution con-

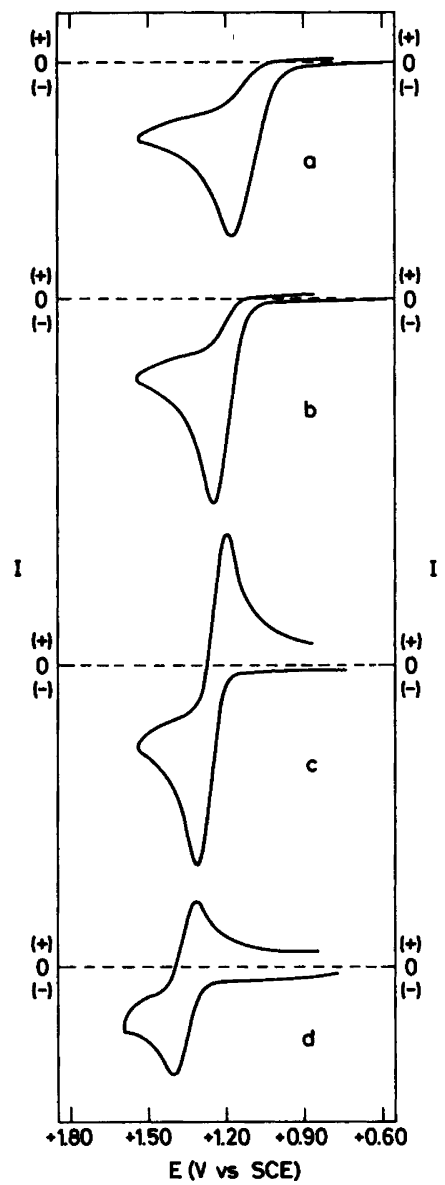

Fig. 1. Cyclic voltammograms for the oxidation of hydroquinone in dichloromethane at $-50^{\circ} \mathrm{C}$ at $86 \mathrm{mV} / \mathrm{s}$. Supporting electrolyte was $\mathrm{Bu}_{4} \mathrm{NBF}_{4}$ $(0.1 \mathrm{M})$. (a) No added acid, (b) $2 \%$ TFA, (c) $2 \%$ TFA and $4 \% \mathrm{MeSO}_{3} \mathrm{H}$ and (d) the same solution as (c) with $3 \% \mathrm{HFSO}_{3}$ added.

taining TFA (2\%), $\mathrm{MeSO}_{3} \mathrm{H}(4 \%)$ and $\mathrm{HFSO}_{3}$ $(3 \%)$ the oxidation of hydroquinone appeared as a quasi-reversible one electron process (Fig. 1d). The decrease in peak height in going from the voltammogram shown in Fig. 1c to that in Fig. 1d was shown to be a consequence of the number of electrons transferred rather than to destruction of substrate by the independence of the peak height on the amount of $\mathrm{HFSO}_{3}$ added. Thus, under the conditions of the experiments, the hydroquinone cation radical is stable.

When an equimolar solution of hydroquinone and quinone in dichloromethane at $-50^{\circ} \mathrm{C}$ was treated with $\mathrm{HFSO}_{3}$, the solution immediately as- 
sumed a deep purple color and the visible absorption spectrum showed a maximum at about $550 \mathrm{~nm}$. One electron oxidation of hydroquinone under the same conditions resulted in a solution of the cation radical which showed a visible absorption spectrum identical to that obtained from the oxidation of hydroquinone by quinone.

The oxidation reaction most likely involves protonation of quinone to the dication $(2,3)$. The reduction potential of the dication (eqn. 8 , Scheme 1 )

$\mathrm{Q}+\mathrm{H}^{+} \rightleftarrows \mathrm{HQ}^{+}$

$\mathrm{HQ}^{+}+\mathrm{H}^{+} \rightleftarrows \mathrm{H}_{2} \mathrm{Q}^{2+}$

is of the order of $500 \mathrm{mV}$ more positive than that for the oxidation of hydroquinone (7). Thus, under conditions where the protonation equilibrium (3) lies far to the right, the equilibrium constant for the electron transfer reaction (4) will be of the order of $10^{8}$ and reaction (4) would be expected to be diffusion controlled. Electron transfer processes involving either quinone (5) or mono-protonated quinone (6) can be ruled out because of very unfavorable equilibrium constants, $10^{-31}$ and $10^{-18}$, calculated from the electrode potentials.

$\mathrm{H}_{2} \mathrm{Q}+\mathrm{H}_{2} \mathrm{Q}^{2+} \rightleftarrows 2 \mathrm{H}_{2} \mathrm{Q}^{+}$

A feature of these reactions of further interest is that the equilibria (2)-(4) are very temperature dependent. The deep purple colored solution of hydroquinone cation radical at $-50^{\circ} \mathrm{C}$ became colorless upon warming quickly to $-10^{\circ} \mathrm{C}$. Rapid cooling of the solution once again to $-50^{\circ} \mathrm{C}$ restored the solution to the original state with very little loss of absorption at $550 \mathrm{~nm}$. Attempts to obtain thermodynamic equilibrium data on reactions (2) - (4) failed due to irreversible side reactions which occur at longer times at temperatures above $-50^{\circ} \mathrm{C}$.

$\begin{array}{ll}\text { Half reaction } & E^{\mathrm{rev}} v s . \mathrm{SCE} \\ \mathrm{Q}+\mathrm{e}^{-} \rightleftarrows \mathrm{Q}^{-} & -0.5 \mathrm{~V}^{15} \\ \mathrm{HQ}^{+}+\mathrm{e}^{-} \rightleftarrows \mathrm{HQ} & +0.2 \mathrm{~V}^{1} \\ \mathrm{H}_{2} \mathrm{Q}^{+}+\mathrm{e}^{-} \rightleftarrows \mathrm{H}_{2} \mathrm{Q} & +1.3 \mathrm{~V} \\ \mathrm{H}_{2} \mathrm{Q}^{2+}+\mathrm{e}^{-} \rightleftarrows \mathrm{H}_{2} \mathrm{Q}^{+} & +1.8 \mathrm{~V}^{a}\end{array}$

Scheme 1. ${ }^{a}$ Value estimated from an irreversible oxidation peak.

The results presented here call attention to an important fact not generally recognised. Protonated intermediates in organic reactions can be powerful oxidants. For example, neither the proton nor quinone are oxidizing agents, the reduction potentials being of the order of 0 and $-0.5 \mathrm{~V}$ ( $v \mathrm{~s}$. SCE), respectively. However, the diprotonated quinone, hydroquinone dication, has a reduction potential of about $+2.0 \mathrm{~V}$ and is a powerful oxidant. Even in cases where the protonated intermediates are present in very low concentration, oxidation reactions can be very rapid since these high potential oxidants may react at diffusion controlled rates. Thus, electron transfer reactions to protonated intermediates is a favorable reaction pathway.

Acknowledgement. This paper was written while V.D.P. was guest professor at the Department of General and Organic Chemistry, the H. C. Ørsted Institute. We gratefully acknowledge the University of Copenhagen for this support.

1. Eggins, B. R. and Chambers, J. Q. J. Chem. Soc. Chem. Commun. (1969) 232.

2. Parker, V. D. J. Chem. Soc. Chem. Commun. (1969) 716.

3. Eggins, B. R. J. Chem. Soc. Chem. Commun. (1969) 1267.

4. Parker, V. D. and Eberson, L. J. Chem. Soc. Chem. Commun. (1970) 1289.

5. Eggins, B. R. and Chambers, J. Q. J. Electrochem. Soc. 117 (1970) 186.

6. Eggins, B. R. J. Chem. Soc. Chem. Commun. (1972) 427.

7. Parker, V. D. Electrochim. Acta 18 (1973) 519.

8. Eggins, B. R. Discuss. Faraday Soc. 56 (1974) 276.

9. Chambers, J. Q. In Patai, S., Ed., The Chemistry of the Quinonoid Compounds, Wiley, London 1974, Part 2, Chapter 14.

10. Yamagishi, A. and Yamada, M. Bull. Chem. Soc. Jpn. 49 (1976) 371.

11. Sep, W. J., Verhoeven, J. W. and de Boer, T. J. Tetrahedron 35 (1979) 2161.

12. Eberson, L., Jönsson, L. and Wistrand, L.-G. Acta Chem. Scand. B. 33 (1979) 413.

13. Eberson, L. Adv. Phys. Org. Chem. 18 (1981). In press.

14. Hammerich, O., Ronlán, A. and Parker, V. D. Acta Chem. Scand. B 30 (1976) 89.

15. Peover, M. E. J. Chem. Soc. (1962) 4540.

Received September 14, 1981. 